\title{
Online community of the Coloured people of South Africa: Vannie Kaap
}

\author{
D. A. Turianitsa ${ }^{1}$
}

${ }^{1}$ Institute for African Studies of Russian Academy of Sciences, 30/1 Spiridonovka str., Moscow 123001, Russian Federation

DOI: $10.18255 / 1996-5648-2021-3-340-349$

Research article Full text in Russian

This article discusses the dynamically developing online community of the Coloured population of South Africa - Vannie Kaap. The author made an attempt to evaluate the importance of this community and trace its history from the moment of its foundation in 2015 to the present day based on materials obtained mainly from the Internet. Particular attention is paid to the consideration and analysis of the causes of this phenomenon, its development and influence of the online group in shaping the images of the Coloured population among other South Africans.

Keywords: South Africa; Colored people; Vannie Kaap; online communities; mem

\section{INFORMATION ABOUT AUTHORS}

\begin{tabular}{l|l} 
Turianitsa, Daria A. & $\begin{array}{l}\text { E-mail: darya.turyanitsa@gmail.com } \\
\text { Postgraduate, Junior Research Fellow }\end{array}$
\end{tabular} 


\title{
Интернет-коммьюнити цветных ЮАР: Vannie Kaap
}

\author{
Д. А. Туряница ${ }^{1}$
}

${ }^{1}$ Институт Африки РАН, ул. Спиридоновка, 30/1, Москва, 123001, Российская Федерация

DOI: 10.18255/1996-5648-2021-3-340-349

УДК 94(680)

Научная статья

Полный текст на русском языке

В статье рассматривается динамично развивающееся интернет-сообщество цветной группы населения ЮАР - Vannie Kaаp . Автор предпринял попытку оценить значение и проследить историю данного сообщества с момента его основания в 2015 г. и до настоящего времени на основе материалов, полученных, главным образом, из сети. Особое внимание уделяется анализу причин возникновения такого рода феномена, его развития и влияния онлайн-группы на фрормирование представлений о цветном населении среди других южноафриканцев.

Ключевые слова: ЮАР; цветные; Фанни Каап; онлайн-коммьюнити; мем

\section{ИНФОРМАЦИЯ ОБ АВТОРАХ}

Туряница, Дарья Андреевна $\mid$ E-mail: darya.turyanitsa@gmail.com

Аспирант, младший научный сотрудник

Интернет-сообщества представляют собой новый ресурс для изучения вопросов истории, культурной памяти, идентичности и репрезентативности ранее "выключенных" из социально-политического поля групп, которые динамично «включаются» в процесс конструирования истории нового южноафриканского общества в фрормате онлайн в XXI веке. Возникновение и создание таких сообществ часто обусловлено поиском решения острых проблем, в результате чего интернет-пространство становится площадкой «для прорабатывания болезненного опыта» [1].

Один из главных «гуру» изучения онлайн-коммьюнити, Генри Дженкинс, писал, что «онлайн-сообщества - платформа для осуществления социального взаимодействия». Самым главным он называет «развиртуализацию пространства», то есть, когда действия и инициативы онлайн-коммьюнити переходят в офрлайн-реальность (например, «Vannie Каaр», проект, о котором речь пойдет ниже).

Обычно публикации в интернете оцениваются количеством откликов, полученных от пользователей сети. В случае с интернет-сообществами

() Туряница Д. А., 2021

Статья открытого доступа под лицензией CC BY (https://creativecommons.org/licenses/by/4.0/) 
Туряница Д. А.

не принципиально, положительные они или отрицательные. Чрезвычайно важен сам фракт реакции со стороны пользователей. Это могут быть комментарии, «лайки» (англ. like - «нравиться»), «шеры» (англ. share - «делиться»), «репосты» (англ. repost - «переотправка»). Хотя все же главное здесь - количество подписчиков группы в социальных сетях.

Глобализация, развитие интернет-технологий привели к созданию интернет-сообществ и в Южно-Африканской Республике (далее ЮАР). Когда идея, технологии и общественный запрос сходятся вместе, рождаются интересные нестандартные проекты, каким и стал «Vannie Kaар».

Южно-Африканская Республика - одно из ведущих государств континента, известное мировому сообществу как страна, в которой в XX веке была установлена система расовой сегрегации - апартеид. Население формально было разделено на несколько групп: «белые», «банту» (черные), «цветные» и «азиаты/индийцы». Все небелые, кроме того, были насильно переселены в специальные зоны: «бантустаны» (что произошло с черными жителями этой страны) или в «тауншипы» ${ }^{1}$, куда в буквальном смысле «загнали» цветную группу населения.

Цветные - многочисленная группа населения Южной Африки, возникшая как результат многовековой расовой политики, как квинтэссенция культур народов трех частей света: африканского, азиатского и европейского. По состоянию на 2019 г. они составляли 8 \% от общего числа населения ЮАР (около 5 млн человек). Их история берет начало в середине XVII в. с появлением первых рабов, привезенных из Юго-Восточной Азии, владений Голландской Ост-Индской компании, Мадагаскара, Восточной Африкки, а также автохтонного населения ЮАР - кой - кой, саан и белых колонистов. «Плавильный котел» культур, языков и религий соединил всех, образовав группу цветных в портовой столице Капской колонии. Неофициально именно Кейптаун стал центром становления идентичности многоликого сообщества ЮАР.

Сложность положения цветных состоит в том, что их нельзя назвать гомогенной группой, как, например, белых и черных южноафриканцев. Неоднородность определялась многими этнокультурными нюансами: внешне их нельзя было отнести ни к белым, ни к черным; цвет кожи значительно мог отличаться даже среди близких родственников; кроме того, одни исповедовали ислам, другие (большинство) - христианство.

После снятия режима апартеида в 1994 г. и прихода к власти АНК, лидером которого являлся Нельсон Мандела, цветные надеялись на улучшение своего «пограничного» положения и рассчитывали на реализацию обещанных социально-экономических изменений. Не получив ожидаемого, они ощутили себя вычеркнутыми из истории своей страны, что привело к полярности точек зрения в их среде относительно собственной идентичности.

${ }^{1}$ Слово «тауншип» (от англ. «township») означает недормальный городской район, куда во времена апартеида принудительно переселялись представители цветного, индийского населения ЮАР. 
Спустя два десятилетия (в 2015 г.) возникла интернет-группа «Vannie Каар». Ее название дословно с капского диалекта языка африкаанс переводится как «Из Капа» - из Кейптауна. Тем самым акцент в названии сделан не на этнорасовый элемент, а на географическую общность людей, проживающих в провинции Западный Кейп.

В одном из интервью основатель коммьюнити, Берни Фабинг ${ }^{2}$ [2] подчеркнул, что идея создания сайта интернет-сообщества пришла не сразу. Первая онлайн-группа в интернет-пространстве появилась под названием «Маненберг». Оно и не случайно. Это имя носит тауншип, откуда родом сам Б. Фабинг. Появление новой онлайн-группы с известным для многих именем заинтересовало пользователей социальных сетей.

Благодаря хорошо продуманным и проработанным постам в течение короткого времени количество подписчиков выросло до трех тысяч. Повышенное внимание «фолловеров» (англ. «follower» - последователь, подписчик) из других районов Кейп Флэтс ${ }^{3}$, куда входит Маненберг, привело создателей сайта к пониманию необходимости заявить о себе в социальных сетях под более широким названием - «Кейп Флэтс». В декабре 2015 г. название «Vannie Каар» было зарегистрировано в социальной сети "Фейсбук», уже имея на тот момент в активе 10 тыс. подписчиков, что дало старт новому этапу развития коммьюнити.

Изначально задача «Vannie Kaар» состояла в создании мемов и мемов с цитатами. Мем - это любая идея, картинка, символ, фотография, которые пользователи интернета осознанно передают друг другу, обмениваясь при этом своими ощущениями от увиденного. Мемы, вызывающие яркие эмоции у интернет-пользователей, стали называться распространителями «вирусных идей». Современные ученые уделяют серьезное внимание изучению природы интернет-мемов. По их мнению, мем в своей комической форме помогает переосмыслять обыденность. Однако такая реальность может быть ложной, что влечет к созданию иллюзорных представлений среди реципиентов мемов. Благодаря шутливой форме мема, его смыслы незаметно внедряются в сознание людей, влияют на их выбор. По этой причине их часто используют в рекламных кампаниях по продвижению товаров.

Созданные "Vannie Каар» мемы не только получили распространение среди цветных, но смогли «пересечь внутриэтнические границы» и завоевать популярность у белых африкаансговорящих ${ }^{4}$. Мемы стали пользоваться огромным спросом. Для удовлетворения все возрастающего интереса пользователей авторам пришлось создать дополнительные странички в социаль-

\footnotetext{
${ }^{2}$ До этого официального интервью Берни Фабинг оставался анонимным автором группы. О нем не знали даже те, кто работал в компании, за исключением Марка Джейкобса.

${ }^{3}$ Кейп Флэтс (англ. Cape Flats) - территория, расположенаая к юго-востоку от Кейптауна. Во времена апартеида это место стало расположением многих тауншипов и неформальных поселений “небелого”населения Южной Африки.

${ }^{4}$ Для этого автор статьи попросила своих знакомых белых африкаанс-говорящих отправить им несколько своих любимым мемов. Среди них были и мемы Vannie Kaаp.
} 
ных сетях - «Твиттер» и «Инстаграм». На страницах газеты «Уикенд Аргус» от 9 апреля 2017 г. владельцы бренда поделились статистикой: на страничке «Vannie Каар» в «Фейсбуке» значится более 185 тыс. подписчиков, что в среднем составляет 5000 новых подписчиков в неделю. В «Инстаграме» - достигли 16 тыс. подписчиков [3]. Наглядно можно отследить рост количества пользователей по двум датам: 1 ноября 2019 г. - «Фейсбук» - 380 тыс. подписчиков, в «Инстаграме» - 151 тыс.; 7 мая 2020 г. - «Фейсбук» - 395,5 тыс. подписчиков, в «Инстаграме»- 180 тыс., в «Твиттере» - 8,7 тыс. Количество фролловеров постоянно растет. Среди подписчиков, как уже отмечалось, есть не только цветные, но и другие южноарриканцы, преимущественно из Кейптауна, и те, кому импонирует контент сообщества.

Параллельно с сообществом на «Фейсбуке» руководители «Vannie Kaар» начали развивать свой собственный новостной сайт - медиапортал «Vannie Kaap News», предлагающий несколько новостных рубрик: «Каар» (то есть новости Западного Кейпа), «Mzansi» (новости ЮАР - так страну называют некоторые афрриканцы) и «Global» (мировые новости).

На стартовой страничке в «Фейсбуке» руководители «Vannie Kaар» отмечают: «Мы существуем для того, чтобы показывать культуру цветных Кейпа и просвещать носителей других культур о наших ценностях. Мы делаем это с помощью забавных мемов, информативных статей, публичных мероприятий <..> и модной одежды» ${ }^{5}$ [4]. Таким способом молодые цветные пытаются напоминать о важности своего места в публичном и информационном пространстве ЮАР, а также развенчать некоторые предубеждения, существующие по отношению к ним.

Авторы постов онлайн-группы используют в основном английский язык и/или капский диалект языка африкаанс (и табуированную лексику), который представляет собой некоторую «упрощенную» смесь африкаанс и английского языка. Они предпочли использовать именно «капскую» фрорму языка афррикаанс, что способствовало ощутимому росту популярности интернет-коммьюнити среди пользователей. Как отмечает южноафриканская студентка С. Роман, написавшая одну из первых научных работ по интернет-сообществу «Vannie Kaар», «капский диалект или, как его еще называют на языке африкаанс, Kaарs ${ }^{6}$, был разговорной фрормой для рабочего класса, в то время как литературная форма языка африкаанс и английского использовалась средним классом цветных и африканерами» [5]. Иными словами, Kaaps pacсматривался как просторечный язык бедноты, а его носителей «клеймили» как представителей низшего слоя общества, вследствие чего бедные слои цветных подвергались двойной стигматизации - по цвету кожи и по языку.

В период режима расовой сегрегации в школах, университетах, в СМИ и среди белого населения чаще всего использовался именно «чистый» лите-

${ }^{5}$ Последнее добавление «модная одежда» появилось с ноября 2019 года.

${ }^{6} \mathrm{~B}$ последнее время можно увидеть неофициальное обозначение капского диалекта языка африкаанс как Afrikaaps, Bruin Afrikaans. 
ратурный африкаанс, а такие диалектные формы, как Kaaps, выходили за общепринятые нормы. Возможно, тогда «чистота» языка зависела напрямую от цвета кожи говорящего, что негативно сказалось на восприятии небелым населением литературной фрормы языка африкаанс. Для них он в ряде случаев ассоциируется как «язык расовой сегрегации» и по сегодняшний день. В интервью С. Роман утверждает, что «люди стыдятся отвечать на Kaaps, если с ними говорят на стандартном африкаанс» [6]. Автор данной статьи имела возможность убедиться в этом на собственном опыте. Впрочем, нельзя забывать, что язык не принадлежит какой-либо группе, а живет и развивается в среде своих носителей независимо от цвета кожи.

Мнения цветных сводятся к тому, что Kaaps, используемый в мемах, возможно, становится выражением протеста против литературной нормы и даже шире - воспринимается среди цветных как борьба с последствиями режима расовой сегрегации, как «деколонизация» на уровне языка.

Удивительный даже для самих создателей успех онлайн-коммьюнити позволил им в 2017 г. открыть собственный первый магазин в Кейптауне, где мемы, которые уже заслужили признание онлайн-пользователей, стали принтами на товарах в реальном магазине. Самые популярные образы с мемов «перекочевали» из онлайн в офлайн, и бренд «Vannie Каaр» стал успешным «цифровым стартапом». Уникальная идея «монетизировалась» и позволила ее обладателям получить определенные доходы, что, безусловно, способствовало дальнейшему развитию успешного интернет бизнес-проекта.

Марк Джейкобс, совладелец бренда в интервью 2017 г. отмечал, что первый магазин на окраине Кейптауна сразу начал приносить доход; в 2019 г. был открыт второй магазин в районе Канал Уолк, а через несколько недель появился магазин и в самом популярном туристическом центре Кейптауна Уотер Фронт [7].

В 2018 г. M. Джейкобс, выступая на радио в Кейптауне, заявил: «Мы, как жители Кейпа, должны привлечь внимание к одному из символов нашего наследия - кусистерс ${ }^{7}$, который якобы «присвоили» себе белые [8]. В октябре 2019 г. совладельцы компании совместно с мэрией Кейптауна организовали Первый праздник Кусистерс (World KOEsister Day). Центральным мероприятием был конкурс на звание «лучшего кондитера кусистерс». Праздник-конкурс удался и получил поддержку не только среди горожан, но и городских властей. В итоге было принято решение праздновать День Кусистерс каждый год, в первое воскресенье сентября. Таким образом низовая инициатива из онлайн-сообества внесла новую культурную струю в общественную жизнь Западного Кейпа.

Авторы бренда предполагают, что в течение ближайших лет бренд вырастет и расширит границы среди подписчиков и почитателей. В их намерения входит открытие еще нескольких магазинов, включая один за границей.

${ }^{7}$ На капском диалекте африкаанс существует форма кусистерс (koesisters) - это южноафриканские сладости, похожие на пончики в кокосовой стружке. 
Туряница Д. А.

Перед авторами проекта стоит еще одна, не менее важная, задача - войти в тройку лучших медиа Кейптауна и значительно расширить свое инорормационное влияние [9].

Тематический анализ публикуемых работ «Vannie Каар» продемонстрировал свойственную им «остроту». Поначалу мемы отличались сильным визуальным разнообразием. Они выглядели вызывающе «разношёрстно». Создатели интернет-сообщества следовали мировым тенденциям и позволяли себе копировать международные шутки, адаптируя их к «своим цветным реалиям». ПРимером может служить весьма популярный в 2019 г. «интернациональный» мем с четырымя разными картинками. В первом квадрате справа - свирепая собака: она не хочет есть брокколи (скорее всего, «негласный» символ правильного питания); на нижнем квадрате справа у нее мирная морда (та же собака готова есть предлагаемую ей самусу (самуса или самоса треугольный пирожок с начинкой, типичный для капско-малайской кухни цветных).

Через некоторое время мемы стали публиковаться уже в «классических тонах» - бирюзовый фрон и белая надпись с определенным шрифтом и со свойственным символом «VK». Например, мем с надписью на капском диалекте переводится как «сегодняшний ветер был недостаточно силен. Я, действительно, думал, он сдует весь мой рождественский жирок».

Всего на данный момент опубликовано более 3600 постов в социальной сети «Инстаграм» ${ }^{8}$. Мемы «Vannie Kаaр» можно разделить на несколько тематических категорий, которые слегка видоизменяются, следуя вызовам времени. Нередко для категоризации постов и быстрого поиска нужной инорормации используются хештеги (\#), однако они не всегда реально обозначают разные темы мемов в «Vannie Kаар». Мемы частично дублируются в разных социальных сетях, тем не менее на протяжении последних трех-четырех лет создатели интернет-сообщества каждый день обновляли посты с цитатами и другими интернет-материалами.

Выделим первую группу мемов в порядке частоты упоминания в интернет-пространстве «Vannie Kaар» - еда; предпочтение отдается капско-малайской кухне. Создатели интернет-сообщества посредством национальных блюд и сопутствующих им бытовых ситуаций проецируют их на традиционные отношения в семье, культуру потребления и расовые особенности. Культура приема пищи и связь с традициями находят существенное отражение в мемах.

Не менее распространенная по числу упоминаний - вторая группа. Она связана с вопросами семейно-брачных связей, например с отношениями внутри семьи: отцов и детей, сестер и братьев, внуков и дедушек/бабушек, - а также с качествами и характеристиками, которыми должен обладать будущий/ая жених или невеста.

\footnotetext{
${ }^{8}$ По данным 24 мая 2020 г.
} 
Третья группа мемов представляется наиболее любопытной, потому что авторы «цветного» коммьюнити создают точные и максимально остроумные мемы; в их основе лежит скрытая критика стереотипов.

Последнюю, четвертую, группу, можно назвать «социальной»; внутри нее на уровне бытовых ситуаций сравнивается реакция белых южноафриканцев и цветных.

Однако время диктует новые подходы и требования. После открытия собственного магазина в 2017 г. и возможного поиска новых клиентов для своего продукта мемы в интернет-группе «Vannie Kaар» претерпели изменения. Некоторые темы ушли на второй план или вовсе перестали освещаться в социальных сетях. Исчезала дихотомия - белые/цветные: последний пост был в 2018 г. с «позитивной» подписью «один за всех и все за одного» [10].

Востребованными оказались новые рубрики, заменившие устаревшую тематику. Дискуссии среди пользователей группы участились, а тема капско-малайской кухни переросла в обсуждение и организацию продаж известного для многих южноафриканцев блюда «куксистерс».

Заслуживают внимания и изменения внутри самого мем-сообщества «Vannie Kaар». Акценты в публикациях группы сместились. К примеру, в указанной группе стали последовательно распространяться хлесткие выражения и цитаты на злобу дня в политическом контексте, комментарии действий лидеров и политических партий ЮАР, критика работы государственного аппарата страны до и во время борьбы с COVID-19 сквозь призму мемов и др.

Одна из тематик, неизменно присутствующая в группе, - саркастический мем, в основе которого лежит новость «сегодняшнего» дня. Разработчики интернет-коммьюнити значительно увеличили количество перепостов в социальной сети «Фейсбук» с собственного сайта новостей «Vannie Kaap News». Разнообразие новостных тем увеличивает зрительскую аудиторию медиаканала и формирует взгляды людей на мировые, южноафриканские, локальные события среди пользователей. Однако пока что данный инфоресурс нельзя назвать эфффективным и масштабным в соотношении с другими южноафриканскими СМИ.

Монетизация сообщества «Vannie Каар» предоставила авторам проекта возможность использовать наиболее яркие формы рекламирования своего продукта. Особо успешной зарекомендовала себя такая форма сотрудничества, как «амбассадор бренда» (от англ. «ambassador» - посол; здесь - человек, продвигающий товар), где «послами» бренда выступали известные медийные личности и наиболее активные постоянные подписчики группы, уважающие и любящие «Vannie Каaр». Популяризации бренда способствовали социально направленные фотографии детей и подростков, одетых в продукцию компании. Такая стратегия предполагает представление бренда в позитивном ключе и тем самым поднимает уровень продаж продукта. 
Туряница Д. А.

Заслуживает особого внимания еще одно важное обновление в мем-группе: впервые стали подниматься вопросы, касающиеся исторической памяти. Поначалу единственным памятным событием, обсуждаемым в постах интернет-группы, была трагическая дата выселения цветных из района Дистрикт 6 в Кейптауне 9 . В последующем добавились интернет-посты, посвященные цветным, оставившим заметный след в истории ЮАР, лидерам движения против апартеида. Публикации подобного рода ретранслировались не только в визуальной/текстовой форме, но и посредством аудио -и видеоконтента. Авторы проекта пытались представить свое видение того или иного события с учетом современных реалий.

Создание и актуальность существования группы «Vannie Каар» обусловлена рядом причин. Главная из них - социальный запрос на репрезентацию цветной культуры в Интернете и общественном пространстве ЮАР, результатом чего стало создание сначала группы по интересам в Фейсбуке, а затем открытие успешного ритейл-магазина. Однако не стоит забывать, что в этих условиях сообщество «Vannie Каар» взаимодействует в основном с теми пользователями, которые имеют возможность выхода в интернет, покупки товаров ритейл-магазина, что доступно немногим в ЮАР. Компания «Vannie Каар» смогла адаптироваться под меняющиеся запросы пользователей, расширив круг вопросов, затрагиваемых через мемы. Победой стало создание и использование мемов на капском диалекте языка африкаанс, что серьезно повлияло на популярность и развитие данного онлайн-сообщества.

«Vannie Kaар» можно рассматривать как платформу для реконструкции или переосмысления («пересборки») элементов идентичности цветного населения; ее «материальная культура» и «символическая культура» поддаются новому толкованию в интернет-пространстве, несмотря на противоречивые взгляды внутри сообщества. Уверенный успех проекта ведет за собой видимые изменения репрезентации цветных и поиска своего места в общественно-культурном пространстве ЮАР. Поднимая в мемах и других постах вопросы историко-культурной памяти, представители коммьюнити сохраняют, дополняют и формируют отношение к своей истории среди своих союзников.

Здесь уместно вспомнить концепцию американского ученого Б. Андерсона о «воображаемых сообществах». В одноименной книге он указывал, что одним из механизмов создания наций послужило развитие «печатного капитализма». Экономическая выгода напрямую двигала поиском новых рынков сбыта товара, которая, в свою очередь, путем распространения книг помогала в продвижении общих идей, языков и в конечном счете самих наций. Идеи Б. Андерсона созвучны тому, как в данный момент времени развивается интернет-сообщество и бренд «Vannie Каaр». С целью привлечения новых сторонников данная онлайн-группа ломает расовые стереотипы среди дру-

${ }^{9}$ Дистрикс 6 - бывший район в центре Кейптауна, объявленный в годы апартеида зоной для «белых». Его жители в 1960-е гг. были насильно переселены в другой район Кейп Флэтс. 
гих южноафриканцев на пути к своему успеху, а также обеспечивает рабочими местами во время глобальной безработицы.

Таким образом, цветные, оказавшись между двух доминирующих культур - «черной» и «белой» - стали, возможно, медиаторами в строительстве южноафриканской “радужной» нации, хотя история сообщества «Vannie Каар» - это только один - частный - ее фрагмент.

\section{Ссылки}

1. Мороз О. В. «Разница в убеждениях - это предмет обсуждения, а не морального уничтожения». 03 октября 2017 // Летняя дискуссионная школа GAIDPARK 2017. URL: http://summer.gaidarfund.ru/articles/2924/tab1 (дата обращения: 04.04.2020).

2. Vannie Kaap founder on his 'wakker' moment in his search for 'colouredness'. 13 марта 2020 // CapeTalk 567FM. URL: http://www.capetalk.co.za/articles/377710/ vannie-kaap-founder-on-his-wakker-moment-in-his-search-for-colouredness (дата обращения: 01.05.2020)

3. 'Vannie Kaap' highlights genuine Cape culture. 9 April 2017 // IOL. URL: https:// www.iol.co.za/news/south-africa/western-cape/vannie-kaap-highlights-genuinecape-culture-8569752 (дата обращения: 05.05.2020).

4. Туряница Д. А. Интернет-мемы как отражение социально-политических проблем современной ЮАР // Материалы XVIII Всероссийской школы молодых африканистов, 26-27 ноября 2019 г. / сост. Н. А. Жерлицына. М.: Институт Африки РАН, 2019. С. 359-363.

5. Samantha Roman. What Kaaps brings to the table: A sociolinguistic analysis of the intersection between, language, food and identity in Vannie Kaap memes. MA Thesis Stellenbosch University. 2019 P. 46. URL: https://www.semanticscholar.org/ paper/What-Kaaps-brings-to-the-table-\%3A-a-sociolinguistic-Roman/23cfc4bffae70 313360cd253da9e643611bc1f26 (дата обращения: 20.04.2020).

6. Samanta Roman. Vannie Kaap memes: an interview with Samantha Roman. 2019-08-23 // LitNet. URL: https://www.litnet.co.za/vannie-kaap-memes-aninterview-with-samantha-roman/ (дата обращения: 02.05.2020).

7. Home-grown fashion in Cape Town: Vannie Kaap. 23 July 2019 // Daily Maverick. URL: https://www.dailymaverick.co.za/article/2019-07-23-home-grown-fashion-incape-town-vannie-kaap/ (дата обращения: 02.05.2020).

8. The sweet and spicy 'marital aid' that is the koesister. 4 October 2019 // The Village News. URL: https://thevillagenews.co.za/the-sweet-and-spicy-marital-aidthat-is-the-koesister/ (дата обращения: 06.05.2020).

9. Local is now 100 \% 'lekker' for Vannie Kaap. 13 May 2018. // IOL. URL: https:// www.iol.co.za/weekend-argus/local-is-now-100-lekker-for-vannie-kaap-14949931 (дата обращения: 04.05.2020).

10. Vannie Kaap. One for all...all for one. \#ubuntu \#vanniekaap 12 June 2018 // Instagram. URL: https://www.instagram.com/p/Bj7bGZZhYVR/ (дата обращения: 05.05.2020). 